\title{
A história marca um gol: aspectos da consciência histórica sobre o futebol amador em São João del-Rei/MG ${ }^{1}$
}

History scores a goal: aspects of historical awareness on the amateur soccer in São João Del-Rei/MG

\author{
Euclides de Freitas Couto* \\ Marcus Vinícius Costa Lage*** \\ Lucas Toledo Gonçalves
}

\begin{abstract}
Resumo
O artigo apresenta reflexões sobre a educação histórica decorrentes da realização do projeto de extensão com interface à pesquisa "A história marca um gol: produção e circulação da memória social do futebol amador em São João del-Rei”. Por meio da análise de narrativas escritas por alunos do Ensino Médio, oriundos de escolas públicas da cidade de São João del-Rei/MG, são avaliadas variáveis que concorrem para elucidar os aspectos relacionados à formação da consciência histórica sobre o futebol amador local.
\end{abstract}

Palavras-chave: Consciência histórica. Futebol amador. São João del-Rei/MG.

\begin{abstract}
This paper presents reflections on history education resulting from a research-associated extension project: "History scores a goal: production and circulation of amateur soccer social memory in São João del-Rei." The variables that contribute to elucidate the aspects related to the formation of historical awareness of local amateur soccer have been analyzed based on written narratives by secondary school students enrolled in public schools in São João del-Rei, MG.
\end{abstract}

Keywords: Historical awareness. Amateur soccer. São João del-Rei/MG.

\section{Introdução}

As reflexões apresentadas neste texto resultam das inquietações e conclusões parciais decorrentes do estudo exploratório, realizado no ano de 2014, que integrou o Projeto de Extensão com Interface à Pesquisa denominado "A história marca um gol: produção e circulação da memória social do futebol amador em São João del-Rei”. Esse projeto teve como objetivo central investigar as formas de apropriação histórica do

\footnotetext{
1 Pesquisa financiada com recursos oriundos da Fundação de Amparo à Pesquisa de Minas Gerais (FAPEMIG).

* Doutor em História pela Universidade Federal de Minas Gerais (UFMG). Professor da Universidade Federal de São João Del-Rei (UFSJ).

** Doutorando em História pela Universidade Federal de Minas Gerais (UFMG).

*** Mestrando em História pela Universidade Federal de São João Del-Rei (UFSJ).
}

Recebido em novembro de 2015 | Aprovado em março de 2016. 
conhecimento sobre o futebol amador na cidade de São João del-Rei/MG na perspectiva da Educação Histórica.

A natureza dúbia do projeto - pesquisa e extensão - favoreceu-nos, num primeiro momento, estimular a memória coletiva da comunidade escolar sobre o futebol amador local, articulando-a aos saberes relacionados às demais especificidades que percorreram o processo histórico da cidade ao longo do século XX. Por meio de exibição de vídeos-documentários e aulas expositivas, a história social do futebol na cidade foi apresentada sob o formato de conteúdo relacionado à História Local nos dois espaços escolares onde o projeto foi desenvolvido. Num segundo momento, os 140 alunos participantes do projeto, com idades entre 14 e 18 anos, do $1^{\circ}$ e $2^{\circ}$ anos do Ensino Médio, foram convidados a representar, por meio da linguagem escrita, suas percepções e saberes sobre a história do futebol na cidade.

Com vistas a uma aproximação introdutória ao nosso tema, o plano conceitual da teoria da consciência histórica, desenvolvida por Jörn Rüsen (2001), é revisitado ao longo do texto, lançando luz sobre as reflexões, que giram em torno das representações históricas sobre o futebol e a cidade, produzidas pelos alunos. Para o filósofo, a operação mental que manipula o conhecimento histórico dialoga diretamente com as experiências do passado, transformadas, inconscientemente, em experiências históricas:

\begin{abstract}
A consciência histórica será analisada como fenômeno do mundo vital, ou seja, como uma forma de consciência humana que está relacionada com a vida humana prática. E este é o caso quando se entende por consciência histórica a suma das operações mentais com as quais os homens interpretam sua experiência da evolução temporal de seu mundo e de si mesmos, de forma tal que possam orientar, intencionalmente, sua vida prática no tempo. (RÜSEN, 2001, p. 57).
\end{abstract}

Nessa direção, a abordagem ruseniana revela que a consciência histórica pode ser verificada quando os sujeitos apresentam dificuldades em construir narrativas históricas coerentes com suas experiências do passado. A aprendizagem histórica ocorre num movimento duplo: num primeiro momento, a mente humana mobiliza fatos objetivos que são apreendidos; posteriormente, os fatos objetivos são subjetivados, ou seja, transformados em conhecimento histórico (RÜSEN, 2001, p. 71). Com efeito, as experiências individuais, inclusive aquelas externas aos espaços escolares, são consideradas pressupostos essenciais no processo de conformação da consciência histórica. 
$\mathrm{Na}$ esteira dessas preposições, a abordagem didática mobilizada ao longo da execução do projeto privilegiou o estímulo da memória dos estudantes sobre o futebol e a cidade, buscando articular as lembranças do esporte e dos espaços públicos (campos de jogo, sedes sociais dos clubes, praças e ruas) aos processos de desenvolvimento urbano e de transformação socioeconômica e cultural que percorreram a vida sãojoanense ao longo do século XX. Em consonância com as prerrogativas teóricas e metodológicas da História Local, as intervenções didáticas aplicadas ao longo do desenvolvimento do projeto privilegiaram o diálogo com o escopo experiencial dos alunos, visando a estimular a construção do conhecimento histórico de maneira compartilhada entre os saberes não-escolares e o conteúdo histórico, num processo dialógico, no qual as representações construídas pelos alunos ganharam sentido ao se articularem aos discursos da história ensinada.

\section{Referencial teórico-metodológico: pressupostos da investigação}

O estudo de caso norteou-se pelo método qualitativo, no qual o foco principal foi direcionado à acumulação de dados descritivos por intermédio do contato direto e interativo entre pesquisador e objeto de estudo, com vistas a analisar a consciência histórica dos alunos. A formação do corpus discursivo, composto pelo conjunto de narrativas escritas, foi estruturado a partir da temática proposta pelas intervenções didáticas conduzidas pelos pesquisadores em sintonia com os planos de ensino de História e Educação Física desenvolvidos pelos professores das respectivas áreas. Desse modo, a opção pela coleta e análise das narrativas ao longo do processo das intervenções didáticas dialoga diretamente com a ideia planteada por Jörn Rusen (2001, p. 154) de que as narrativas são modelos de construção de sentido, ou seja, formas argumentativas de exteriorização da consciência histórica.

O projeto se desenvolveu na cidade de São João del-Rei, localizada na microrregião do Campo das Vertentes, no estado de Minas Gerais. De origem colonial, a cidade se transformou no final do século XIX em um dos mais importantes centros comerciais do Estado, destacando-se pela exportação de produtos manufaturados e matéria-prima como algodão, madeira, manganês etc. (GRAÇA FILHO, 2002). Em 1881, após a inauguração da Estrada de Ferro Oeste de Minas (EFOM), a cidade experimentou um frenético processo de crescimento urbano e diversificação das 
atividades culturais decorrentes, sobretudo, das intensas trocas simbólicas com a capital da República, à época o Rio de Janeiro.

No bojo desses acontecimentos, o futebol se instalou na cidade, tornando-se uma das práticas de lazer mais importantes para as classes dominantes locais. Após a fundação de duas agremiações da "boa mocidade" nos anos de 1900/1910 - o Athletic Club $^{2}$ (1909) e o Santo Antônio Foot-Ball Club (1914) - e com o surgimento do Minas Football $C l u b^{3}$ em 1916, o esporte se espalhou rapidamente entre os estratos populares, uma vez que a agremiação fundada no bairro do Tijuco, localizado na periferia da cidade, abriu a oportunidade para a associação dos moradores locais (LIMA, 2014, p. $85)$.

Embora o advento da profissionalização do futebol, a partir da década de 1930, não tenha alterado a configuração dos clubes são-joanenses, o entusiasmo dos torcedores com o futebol local foi se ampliando na medida em que os campeonatos organizados pelas ligas amadoras, desde 1944, atraíam um público cada vez mais numeroso para as tardes esportivas (LIMA, 2014, p. 84). O enraizamento do futebol amador na cidade fomentou o surgimento de rivalidades locais e de vínculos afetivos e identitários entre os habitantes e seus clubes. Tais manifestações, presentes, sobretudo, no universo masculino, expressas na forma de pertencimento clubístico ${ }^{4}$, são mobilizadas pelas práticas de torcer, pelo chiste, pelas jocosidades e por uma constelação de engajamentos que ultrapassam a esfera esportiva. Ao assumir centralidade na sociabilidade local, o futebol amador se constitui, portanto, um bem cultural da cidade. Nessa perspectiva, ao se entrelaçar aos inúmeros aspectos da História Local, sua transposição didática como conteúdo histórico possui enorme potencialidade para o entendimento do cotidiano são-joanense e da circularidade cultural entre as cidades no século XX.

\footnotetext{
${ }^{2}$ Fundado em 1909, com o nome de Athletico Club, em 1913, teve o nome modificado para Athletic Club, quando seus associados vislumbraram que o clube poderia abrigar diferentes modalidades esportivas, conforme indica o registro na reunião da diretoria na Ata da $1^{\text {a }}$ Sessão Extraordinária Inaugural do "Athletic Club" realizada no dia 10 de agosto de 1913, p. 2.

${ }^{3}$ Embora seu campo estivesse localizado na periferia da cidade, o Minas surgiu de uma dissidência da diretoria do Athletic Club, fato que lhe conferiu ao longo da sua história um perfil social ambíguo, já que seus associados se dividiam entre a "boa mocidade" são-joanense e indivíduos provenientes dos estratos populares (LIMA, 2014, p. 80).

${ }^{4}$ Segundo o antropólogo Arlei Damo (2012, p. 51-52), no universo masculino, o pertencimento clubístico é um tipo de identidade social construída essencialmente por uma fidelidade "eterna", que geralmente é transmitida numa relação de honra masculina. Assim, assumir o papel social de torcedor implica, necessariamente, assumir uma série de códigos de comportamento e fidelidade que independem, muitas vezes, das suas vinculações extrafutebolísticas.
} 
As ações extensionistas e a pesquisa de campo se desenvolveram em duas escolas da rede estadual de ensino da cidade de São João del-Rei/MG. Em linhas gerais, esses espaços escolares apresentam características que nos permitem dotá-las de certa homogeneidade: dispõem de considerável espaço físico e infraestrutura que comporta o desenvolvimento de uma gama de atividades curriculares e extracurriculares. As similitudes encontradas entre elas se estendem também a outros aspectos como o contingente de alunos e educadores, a oferta de aulas em três turnos e as parcerias institucionais firmadas com a Universidade Federal de São del-Rei (UFSJ) por meio do Programa Institucional de Bolsas de Iniciação à Docência (PIBID).

A primeira escola, a qual optamos por nomeá-la de Escola 1, localiza-se em um bairro operário da cidade, que se desenvolveu ao longo do século $\mathrm{XX}$ decorrente de intensos processos de industrialização e de expansão territorial motivados, sobretudo, pela chegada da Estrada de Ferro Oeste de Minas, que ligava São João del-Rei à cidade do Rio de Janeiro, a então capital da República. É a maior escola do município e aquela que apresenta o recorte social mais heterogêneo social de sua clientela. Sua clientela pode ser dividida entre os alunos que residem na própria região, formada por bairros operários; por aqueles que residem em áreas mais nobres, como no centro da cidade; e também por estudantes oriundos de bairros periféricos e pauperizados. Estudam no turno da manhã alunos do $9^{\circ}$ ano do Ensino Fundamental e Médio (com turmas do $1^{\circ}$ ao $3^{\circ}$ ano). No turno da tarde, estudam os alunos do Ensino Fundamental do $1^{\circ}$ ao $8^{\circ}$ ano. O noturno abriga alunos do Ensino Médio com turmas do $1^{\circ}$ ao $3^{\circ}$ ano. A instituição fornece aos estudantes acesso aos instrumentos tecnológicos de informação que, embora encontrados cada vez mais difundidos no meio social, lhes proporciona um horizonte maior de pesquisa e de novas formas de interação no ambiente escolar. O trabalho de pesquisa na Escola 1 consistiu na análise de informações coletadas de jovens das duas turmas do $1^{\circ}$ ano do Ensino Médio - $1^{\circ} \mathrm{A}$ e $1^{\circ} \mathrm{B}-$, que possuem entre 14 e 17 anos de idade, representando um total de 46 alunos.

A segunda escola, nomeada de Escola 2, encontra-se situada em um dos bairros mais populosos da periferia de São João del-Rei e conta, também, com alunos oriundos de comunidades vizinhas, consideradas periféricas e pobres. Nessa escola, são oferecidos o Ensino Fundamental, com turmas do $6^{\circ}$ ao $9^{\circ}$ ano no turno vespertino, o Ensino Médio, com turmas do $1^{\mathrm{o}}$ ao $3^{\mathrm{o}}$ ano, no matutino e a Educação de Jovens e Adultos (EJA) e o Técnico em Informática (PRONATEC) no noturno. Entre as propostas pedagógicas desenvolvidas pela escola, destacam-se aquelas que buscam 
aperfeiçoar a qualidade do ensino por meio do uso da informática e de práticas interdisciplinares. Os dados recolhidos na Escola 2 são decorrentes do trabalho extensionista realizado com 94 jovens das três turmas do $2^{\circ}$ ano $-2^{\circ} \mathrm{A}, 2^{\circ} \mathrm{B}$ e $2^{\circ} \mathrm{C}-$, que estão na faixa etária compreendida entre 14 e 18 anos.

Durante a fase de planejamento do projeto, ao deparamos com diferenças significativas entre os conteúdos previstos para as mesmas séries em cada uma das escolas, optamos por selecionar a amostra buscando priorizar a homogeneidade de variáveis como a faixa etária e a condição socioeconômica dos participantes, em detrimento ao ano de curso do Ensino Médio. Outrossim, as disparidades relativas ao número das turmas selecionadas em cada escola e também à sua seriação, se deveu, especialmente, à disponibilidade de classes oferecidas por cada escola ${ }^{5}$ e ao conteúdo programático previsto no plano de ensino para cada uma delas.

Ao longo do processo de planejamento e estruturação das ações extensionistas, recorremos ao conceito de "formas de conhecimento" cunhado por Verônica Edwards (1997). Ao articular as dimensões do "conhecimento" e da assimilação dos atores, essa ferramenta conceitual se coaduna aos nossos objetivos de investigar as formas de apreensão do conhecimento histórico. Nessa ótica, a utilização do conceito se mostrou condizente ao objetivo central do projeto, que se propõe a identificar os níveis de consciência histórica relativa aos saberes da História Local disseminados entre os alunos.

Edwards (1997), ao formular o conceito denominado "formas de conhecimento", subdividiu-o em três categorias. A primeira categoria é denominada forma de conhecimento utópico, cujo foco da aprendizagem está direcionado na fixação dos conteúdos de maneira isolada das referências extraescolares, sem que os saberes escolares sejam articulados ao conhecimento prévio dos alunos (EDWARDS, 1997, p. 21). Aos estudantes, é apresentado um modelo de conhecimento histórico que se impõe como uma "verdade absoluta", de maneira que suas pré-noções e interpretações são descartadas. A segunda categoria recebe o nome de forma do conhecimento como operação e sugere interação entre alunos e professores. Ao longo das atividades delineadas por essa estratégia, os jovens são instruídos a aplicarem seu conhecimento em alguma situação prática, conduzida no escopo de uma intervenção didática (EDWARDS, 1997, p. 156). A terceira forma de conhecimento foi designada como

\footnotetext{
${ }^{5} \mathrm{Na}$ Escola 1, ofereciam-se 2 turmas de $1^{\circ}$ ano do Ensino Médio, enquanto na Escola 2, ofereciam-se 3 turmas do $2^{\circ}$ ano do Ensino Médio.
} 
forma de conhecimento situacional e é caracterizada pela intencionalidade de conhecer e tornar inteligível a realidade dos atores. Para a autora, é uma espécie de “[...] saber centrado num ponto de intersecção entre o mundo e o indivíduo para o qual o dito mundo é significativo" (EDWARDS, 1997, p. 164).

Ao nos apropriarmos dessas duas últimas categorias, ou seja, a forma de conhecimento como operação e a forma de conhecimento situacional, a abordagem didática que levamos a cabo ao longo da execução do projeto procurou estimular a memória dos alunos por meio de aulas expositivas e vídeos-documentários. Além de lançar mão de tais estratégias, convidamos os alunos a entrevistarem pessoas de seu convívio que possuíam alguma ligação com o futebol amador (dirigentes, técnicos e/ou jogadores). O conjunto dessas ações procurou estimular nos jovens a percepção sobre seu pertencimento à cultura local à medida que seus vínculos afetivos e identitários foram mobilizados no processo de construção do conhecimento histórico.

Nessa direção, a ação pedagógica pautada ao longo do projeto buscou articular a estratégia didática da forma de conhecimento como operação e a forma de conhecimento situacional à perspectiva teórica da História Local. Na ótica de Schmidt e Cainelli (2009, p. 113), a História Local, como um instrumento estratégico de aprendizado, pode apresentar melhores resultados na apropriação do saber histórico fundamentado em recortes predeterminados do conteúdo, que serão integrados, posteriormente, ao conjunto do conhecimento.

O interesse pela História Local cresceu de maneira significativa no Brasil, especialmente após os anos 1990. Os Parâmetros Curriculares Nacionais (PCN), elaborados pelo Ministério da Educação, a tornaram uma proposta temática nos primeiros anos do Ensino Fundamental e prática metodológica nos demais anos do ciclo básico. A História Local permite conexão e desenvolvimento da ideia de pertencimento dos alunos a um determinado meio cultural e social, possível mediante análise das formas de viver no passado e no presente de tal região (GERMINARI, 2014).

A História Local se configura também como importante aliada no próprio ensino da disciplina História, pois objetiva aperfeiçoar a formação da consciência histórica dos jovens. Seguindo nessa direção, Schmidt (2007) destaca que,

[...] ao se propor o ensino de História Local como indicativo da construção da consciência histórica, não se pode esquecer de que, no processo de globalização [em] que se vive, é absolutamente indispensável que a formação da consciência histórica tenha marcos de referência relacionais e identitários, os quais devem ser conhecidos e situados em relação às identidades locais, nacionais, latino-americanas e mundiais. (SCHMIDT, 2007, p. 190). 
Em diálogo com tais pressupostos teóricos, o trabalho realizado com os 46 jovens da Escola 1 e 94 jovens da Escola 2 respeitou uma ordem preestabelecida de atividades. Em um primeiro momento, consistiu na realização de três aulas temáticas e expositivas:

- $1^{\text {a }}$ aula: a origem do futebol no Brasil, seus principais aspectos de desenvolvimento e expansão e sua penetração simbólica e cultural no País;

- 2a aula: a história do futebol em São João del-Rei/MG, sua origem, principais clubes, curiosidades e consolidação de uma tradição futebolística amadora. ${ }^{6}$

- $3^{\text {a }}$ aula: foi aplicada uma proposta de atividade complementar desenvolvida pelos alunos em forma de produção de texto em sala de aula. Nessa atividade, os alunos deveriam expor, por meio da linguagem escrita, seus conhecimentos e, principalmente, seus sentimentos, vivências e interpretações sobre o futebol amador local. Para tanto, os jovens foram orientados a se embasar em seus próprios conhecimentos e experiências, buscando articulá-los aos conteúdos apresentados nas aulas expositivas e nos vídeosdocumentários.

Os materiais audiovisuais apresentados, especialmente na $2^{\mathrm{a}}$ aula, se originam de um acervo levantado por uma pesquisa anteriormente realizada na cidade. O Projeto de Pesquisa "Nas vertentes do futebol: higienização, catalogação, fotodigitalização e organização dos acervos documentais das agremiações esportivas de São João del-Rei” foi responsável pelo levantamento da documentação de três entidades esportivas da cidade: Athletic Club (1909), Minas Futebol Clube (1916) e Liga Municipal de Desportos (1944), cujo produto final consistiu na organização do acervo documental das referidas agremiações, bem como na edição de um CD-ROM que abriga um banco de dados e material audiovisual relativos à documentação das entidades.

As aulas foram ministradas pelos pesquisadores em parceria com os professores de Educação Física e História das escolas, por meio de uma ação interdisciplinar que possibilitou o ensino e a interlocução dos conhecimentos histórico e teórico relativos às práticas esportivas desenvolvidas pelos alunos na disciplina. Com vistas a garantir a

\footnotetext{
${ }^{6}$ É importante mencionar que ao final da segunda aula foi proposta uma atividade extraclasse que consistiu na gravação de uma entrevista na qual os alunos deveriam buscar relatos de familiares, amigos ou vizinhos que possuíssem ligação com o futebol amador local. De posse de um pequeno questionário formulado pelos pesquisadores e fazendo uso da câmera de aparelho celular, os estudantes deveriam gravar os depoimentos e apresentá-los no próximo encontro com os pesquisadores. Embora boa parte dos estudantes tenha retornado com os registros audiovisuais, eles não foram incorporados ao corpus documental cotejado neste artigo.
} 
autenticidade da autoria, a proposta da atividade de produção de texto foi apresentada aos estudantes com a orientação de ser realizada em sala de aula.

\section{Referencial teórico-metodológico: a análise das narrativas}

Embora escape aos propósitos deste artigo desenvolver uma exegese dos quadros teóricos das narrativas, com vistas a uma preparação heurística do aporte teórico mobilizado no exercício de análise do material produzido pelos alunos, além do conjunto de referências teórico-metodológicas mobilizadas para sustentar e nortear a investigação do objeto de pesquisa, recorremos às lentes interpretativas produzidas pela Epistemologia da História e pela Filosofia da Educação.

Ao creditar à narrativa o valor de uma operação mental da consciência histórica, o epistemólogo Jörn Rüsen (2001) procura compreendê-la como uma construção de sentidos ancorada nas experiências práticas da vida humana. Com efeito, nessa acepção

[...] as experiências do tempo são interpretadas com relação às formas de agir e, enquanto interpretadas, inserem-se na determinação do sentido do mundo e na autointerpretação do mundo do homem, parâmetros de sua interpretação no agir e no sofrer (RÜSEN, 2001, p. 59).

Em contraposição à esfera do mundo das ações práticas, a consciência histórica não estaria diretamente relacionada à racionalidade teleológica do agir humano, mas à conformação de racionalidades que irão operacionalizar a relação humana com as experiências temporais. Nesse sentido, as narrativas constituem-se como operações mentais que, produzidas a partir de experiências singulares com o tempo, procuram dominá-lo, controlá-lo, tornando-o inteligível e, portanto, narrável.

Ademais, na concepção ruseniana, as experiências do tempo não podem ser explicadas prontamente, pois se constituem como parte do "sofrimento" da vida humana. O tempo vivido, nesse aspecto, não é passível de interpretações imediatas, uma vez que o homem tem necessidade de formular um "quadro interpretativo" sobre sua relação com o tempo, designando continuidades, rupturas e tensões por meio das quais sua vida é moldada e condicionada. O exercício de interpretação que conduz o sujeito ao "domínio" do tempo é, portanto, uma operação de segunda ordem, responsável pela coordenação e ajustamento das maneiras de pensar e das condutas objetivas da ação.

Desse modo, Rüsen (2001) rompe com o paradigma estruturalista-objetivista materializado, por exemplo, nas Teses sobre Feuerbach, obra marxiana na qual a 
apreensão do mundo pode ser realizada a partir de um registro, ou seja, em que as ações humanas podem ser condicionadas por uma relação imediata e mecânica com a realidade posta sem que haja a intermediação da subjetividade do sujeito. Sob esse aspecto, as análises rusenianas aproximam-se dos pressupostos da teoria praxiológica de Pierre Bourdieu (2011), na medida em que postulam um caminho alternativo à dicotomia individualismo/holismo, no debate sobre a ação individual e a coletividade (estruturas) como forças motrizes da explicação sociológica.

Na mesma direção, ao investigar heuristicamente a relação entre os estudantes e os saberes históricos, o filósofo da educação, Husbands (2003 apud SCHIMIDT, 2008, p. 86), avalia que uma das maneiras de compreender o entendimento dos estudantes sobre o passado é identificar, no interior das narrativas, os elementos elencados por eles no exercício de interpretação das diversas temporalidades. Nessa ótica, suas análises alertam para o fato de que as narrativas espontâneas são carregadas de interpretações pessoais, motivadas, em suma, por transposições didáticas equivocadas e/ou interpretações ilustradas por personagens e agentes históricos que são (re)criados e interpretados sem o devido rigor científico pelos estudantes. As análises de Husbands (2003, p. 39 apud SCHMIDT, 2008, p. 86), nessa visão, se aproximam das lentes interpretativas criadas pelos interacionistas simbólicos norte-americanos ${ }^{7}$. Ao recorrer à categoria "interação" no exercício da compreensão dos processos de interações sociais presentes na dinâmica do ensino e da aprendizagem, Husbands move-se no terreno das subjetividades e das trocas simbólicas promovidas entre os agentes no bojo do processo educativo. Nessa perspectiva, especialmente no que tange à concessão de uma prioridade metodológica, caberia ao professor a tarefa de se posicionar como um investigador social, buscando mediar e orientar a construção do saber histórico a partir do conhecimento prévio dos alunos, como também interpretá-lo, valendo-se dos conteúdos explícitos nas narrativas.

Em diálogo com os espectros teóricos expostos anteriormente, uma questão que se apresenta na tarefa de interpretar a consciência histórica dos estudantes diz respeito ao método a ser empregado no exercício de análise das narrativas. De modo geral, a tarefa de análise e classificação das narrativas, que visa a mensurar a compreensão dos estudantes sobre determinado saber histórico, esbarra em valores tacitamente incorporados pelo professor ao longo das suas trajetórias acadêmica e profissional, que

\footnotetext{
${ }^{7}$ Referimo-nos, especialmente, à vasta obra produzida pelo filósofo Georg Hebert Mead.
} 
são revividos no processo de avaliação. Dessa forma, no sentido de se formular e executar uma ação avaliativa condizente com a produção do saber histórico, torna-se imprescindível a adoção de modelos heurísticos capazes de aguçar e padronizar a interpretação sobre os níveis de compreensão do conteúdo histórico apresentado nas narrativas. Nesse sentido, as tipologias de interpretação das narrativas de estudantes criadas pela historiadora Regina Parente (2009, p. 99-100) constituem-se como um valioso aporte teórico-metodológico, que se adequam às propostas empíricas de investigação de narrativas históricas. Elas se encontram organizadas conforme o Quadro 1.

\section{Quadro 1 - Modelo de compreensão das narrativas}

\begin{tabular}{|c|c|}
\hline \multicolumn{2}{|r|}{ ESTRUTURA NARRATIVA } \\
\hline NÍVEL 1 & $\begin{array}{l}\text { Fragmentos } \\
\text { Frases soltas sem ligação entre os passos. Colagem de tempos, espaços, fatos, } \\
\text { acontecimentos e protagonistas, sem grande rigor histórico, apresentados por meio de uma } \\
\text { sequência organizativa simples a partir de uma seleção, por vezes incoerente de algumas } \\
\text { fontes, sobretudo do texto e da cronologia, podendo afastar-se parcialmente do assunto } \\
\text { histórico em causa. }\end{array}$ \\
\hline NÍVEL 2 & $\begin{array}{l}\text { Descricão Alternativa } \\
\text { Relato com coerência interna numa forma algo fragmentada e simples, apresentando uma } \\
\text { estória dentro da história, que se resume apenas a pequenos detalhes dispersos sobre o } \\
\text { assunto histórico em causa. }\end{array}$ \\
\hline NÍVEL 3 & $\begin{array}{l}\text { Descricão Simples } \\
\text { Narrativa composta por partes de texto, apresentando ligações implícitas entre os passos e } \\
\text { outras partes em frases soltas que, embora com uma argumentação simples na qual se } \\
\text { detectam implicitamente referências a intenções e objetivos, carecem de lógica interna. }\end{array}$ \\
\hline NÍVEL 4 & $\begin{array}{l}\text { Descricão com Coerência } \\
\text { Narrativa emergente, apresentando uma estrutura narrativa visível por meio de um fio } \\
\text { condutor que deixa perceber ligações implícitas e explícitas entre os diferentes passos, } \\
\text { com uma lógica interna, com uma argumentação histórica simples, descrevendo algumas } \\
\text { ações claramente, mas deixando por explicar as causas dos acontecimentos. }\end{array}$ \\
\hline NÍVEL 5 & $\begin{array}{l}\text { Descricão Explicativa } \\
\text { Narrativa elaborada com lógica interna, apresentando uma evidente estrutura narrativa por } \\
\text { meio de uma sequência organizativa coerente. Há ligações causais implícitas e explícitas } \\
\text { entre os acontecimentos, justifica as ações dos protagonistas, fazendo, em algumas } \\
\text { situações, interferir explicitamente as consequências e os resultados desses } \\
\text { acontecimentos e ações, e manifestando compreensão histórica da situação. }\end{array}$ \\
\hline NÍVEL 6 & $\begin{array}{l}\text { Descricão Explicativa Contextualizada } \\
\text { Narrativa elaborada com lógica interna, apresentando uma evidente estrutura narrativa por } \\
\text { meio de uma sequência organizativa coerente. Apresenta ligações causais implícitas e } \\
\text { explícitas entre os acontecimentos, justifica as ações dos protagonistas fazendo interferir } \\
\text { explicitamente as consequências e os resultados desses acontecimentos e ações. Manifesta } \\
\text { poder de síntese e compreensão histórica da situação. }\end{array}$ \\
\hline
\end{tabular}

Fonte: (PARENTE, 2009, p. 99-100). 
Com base nos pressupostos descritos acima, a análise quantitativa das narrativas foi direcionada, preliminarmente, com o intuito de aferir os níveis de profundidade da prática discursiva dos estudantes. A partir dessa triagem, foi executada uma seleção temática, da qual logramos agrupar e quantificar os assuntos mais recorrentes encontrados nos discursos escritos. Por último, por meio de uma abordagem qualitativa, buscamos problematizar o conteúdo das narrativas, com vistas a debatê-los à luz de questões sociológicas que permeiam o campo futebolístico e o ensino de história.

\section{Resultados provisórios da pesquisa}

A análise da produção escrita decorrente das atividades realizadas nas Escolas 1 e 2 incidiu sob as narrativas elaboradas a respeito do conhecimento e das experiências acerca do futebol amador em São João del-Rei/MG. Foi agrupado um total de 140 textos, cujos conteúdos foram classificados de acordo com os critérios elaborados por Parente (2009). Nessa ótica, a classificação das narrativas em seis níveis de análise permitiu identificar os parâmetros da compreensão histórica expostos pela linguagem escrita dos estudantes.

\section{Gráfico 1 - Características das Narrativas}

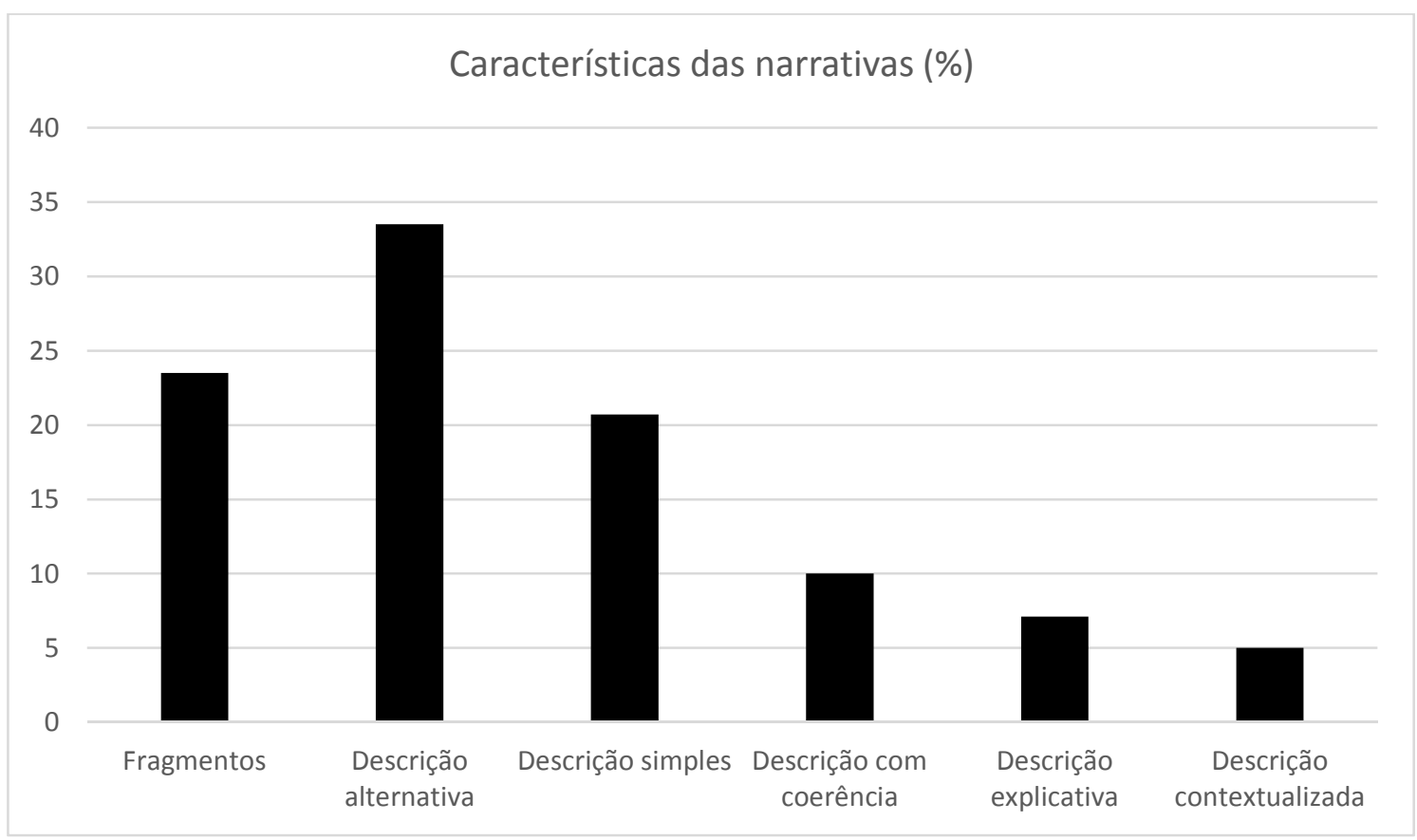

Fonte: Elaborado pelos autores. 
A análise do cômputo final referente ao conjunto das narrativas revela que houve a predominância dos relatos tipificados como fragmentos e descrição alternativa níveis 1 e 2, respectivamente - que corresponderam a 57\% das produções escritas. Esse dado nos possibilita desvelar a interferência de conhecimentos extraescolares no processo de aprendizagem dos conteúdos históricos, na medida em que as explicações sobre a história se assentam, em parte significativa das amostras, em informações veiculadas pelos meios de comunicação de massa. Tal questionamento se torna ainda mais plausível quando recorremos à concepção ruseniana de narrativa vinculada a uma operação mental da consciência histórica articulada às experiências práticas do cotidiano humano (RÜSEN, 2001). Os jovens, de acordo com esse ponto de vista, apresentaram dificuldades em compreender com exatidão a proposta de atividade que lhes foi sugerida. Além do mais, demonstraram confusões conceituais ao introduzir nesse exercício os conteúdos e a natureza histórica de suas existências, bem como as relações temporais que imperam nessas experiências. Dessa maneira, boa parte dos estudantes encontrou dificuldade em construir narrativas com descrição explicativa e descrição explicativa contextualizada, além de não elencarem conhecimentos históricos coerentes à explicação do processo de enraizamento e difusão do futebol amador na cidade ao longo do século XX.

A partir da identificação desses parâmetros de compreensão, foi possível encontrarmos a existência de elementos estruturantes por meio dos quais os estudantes definiram o eixo principal que conduziu a argumentação textual. Entre eles, selecionamos os que foram mobilizados com maior frequência pela produção escrita em questão:

\section{Gráfico 2 - Elementos Estruturantes presentes nas narrativas}

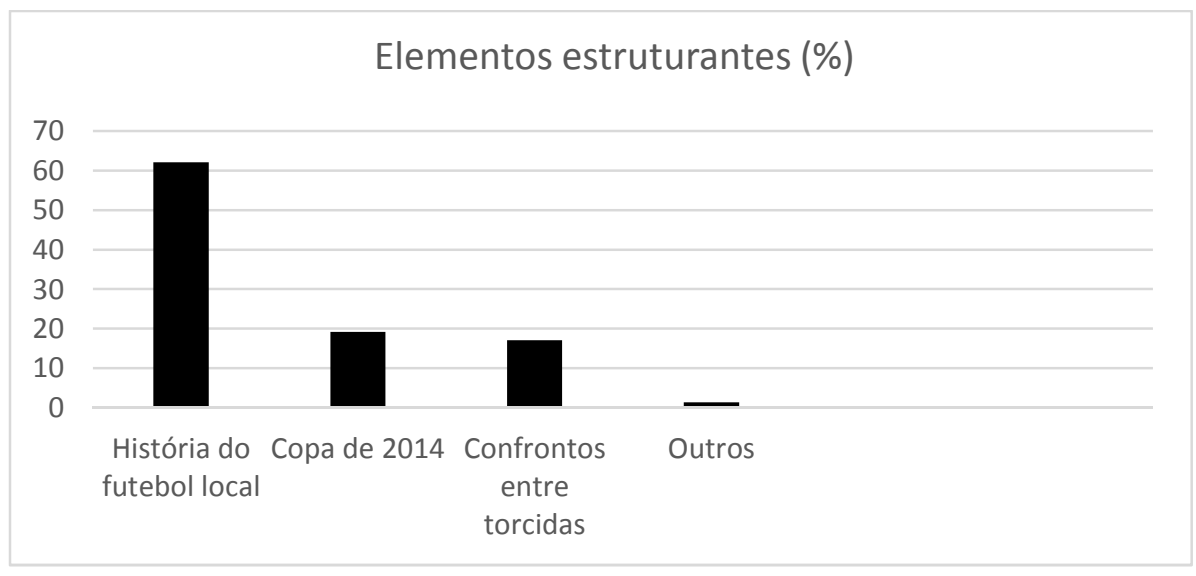

Fonte: Elaborado pelos autores. 
Com vistas ao aprofundamento sobre a compreensão das temáticas enunciadas pelos textos, também merecem destaque as ideias substantivas que foram elencadas pelas narrativas. Para a computação dos dados, vale ressaltar que no total de 140 redações, cuja separação por temas estruturantes foi identificada no Gráfico 2, as ideias substantivas, invariavelmente, se repetiram dentro de um mesmo tema estruturante. Portanto, a variação da sua porcentagem se refere ao total de narrativas.

\section{Gráfico 3 - Ideias substantivas}

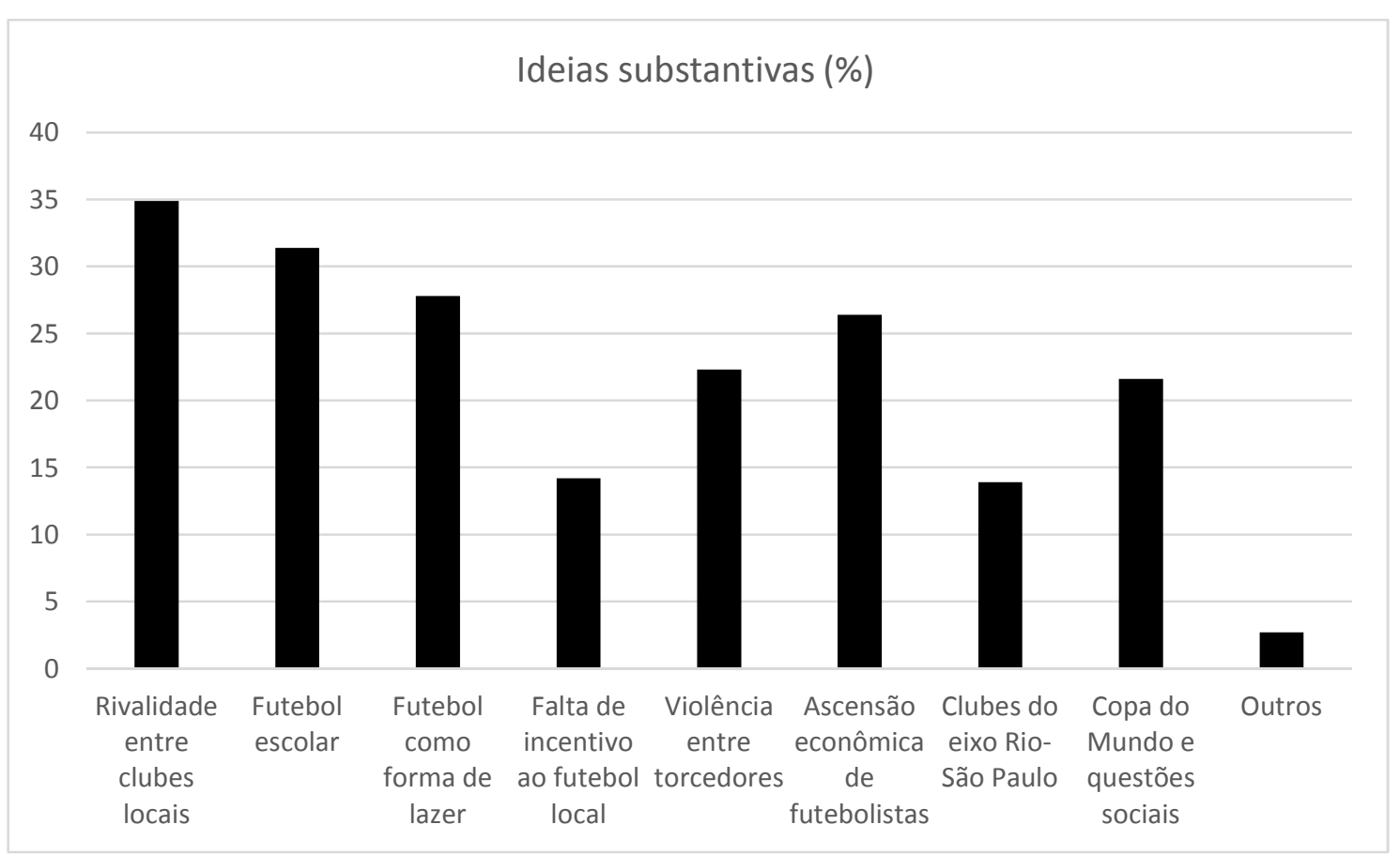

Fonte: Elaborado pelos autores.

De modo geral, o elemento estruturante mais recorrente nas narrativas (Gráfico 2) se relaciona à proposta temática solicitada pela atividade de produção de texto desenvolvida ao longo da $4^{\mathrm{a}}$ aula, ou seja, as percepções, informações, dados históricos e "histórias" relacionadas ao futebol amador local.

Em um tempão atráz [sic], quando meu avô era novo, o futebol aqui em São João del-Rei estava no auge. Já existiam vários times: América, Minas, Nacional, Social, Atletitic [sic]. O campo onde os jogos aconteciam era muito frequentado por pessoas de toda região. O meu avô, por exemplo, morava em um bairro rural, mais [sic] ele me disse que só foi uma vez ver o jogo do Minas X Atletic [sic]. Ele ficou encantado. (Fragmento de narrativa produzido por uma aluna da turma $1^{\circ} \mathrm{B}$, Escola 2). 
Intitulada "Futebol no campo rural", a redação acima revela aspectos importantes da história local de São João del-Rei. Referindo-se à memória do seu avô, que vivenciou, ao longo das décadas de 1960 e 1970, as "décadas de ouro" do futebol amador na cidade, a aluna constrói um relato extremamente coerente com a dinâmica urbana da época. De fato, os registros históricos revelam que, nesse período, o derby disputado entre Minas e Athletic despertava grande interesse da população da cidade e da região, sendo considerado pela imprensa local o principal evento da cidade (LIMA et al., 2009, p. 10).

Embora se reconheça que o entendimento sobre realidade local deva ser articulado às questões nacionais e mundiais, o relato acima indica que, ao mobilizar os aspectos afetivos da sua memória relacionada à inserção da sua família no futebol local, a aluna revela vínculos identitários profundos com a realidade local, indicando, por seu turno, que suas referências históricas particulares estabelecem uma fina sintonia com os aspectos do desenvolvimento histórico do esporte e do espaço urbano onde vive. Assim, ao articular a história à vida cotidiana, o estudo da localidade apresenta-se como uma importante estratégia pedagógica na direção de possibilitar a transposição do saber histórico para o saber escolar.

Ocupando-nos da análise do plano geral dos registros escritos, notamos que aproximadamente $70 \%$ dos estudantes abordou algum aspecto relacionado à história do futebol local, embora parte significativa dessas narrativas apresentou, associada a essa temática, informações sobre os grandes clubes de futebol profissional, sobre a realização da Copa do Mundo ou sobre as brigas entre torcedores:

\footnotetext{
O futebol é assim, traz paixão, grandes emoções, mas um problema que está acontecendo hoje é [sic] as brigas nas torcidas. Isso é ruim, faz menos pessoas assistirem o futebol. (Fragmento de narrativa produzida por um aluno da turma $1^{\circ} \mathrm{C}$, Escola 2).

Hoje em dia o fanatismo pelo futebol passa da conta, por isso para mim é bem melhor assistir ao jogo pela TV, do que no estádio. (Fragmento de narrativa produzido por uma aluna da turma $1^{\circ} \mathrm{B}$, Escola 2 ).
}

A incidência significativa dessa informação nos registros $(17,1 \%$ dos elementos estruturantes e 22,3 das ideias substantivas) nos sugere conjecturar que a abordagem conferida a esse tipo de ocorrência pela grande imprensa brasileira instaurou a questão no centro das discussões relacionadas ao futebol no país. Como fica evidente na análise das expressões textuais em questão, quando os estudantes foram estimulados a descrever suas experiências relacionadas ao futebol amador, a violência entre torcedores 
organizados, embora não faça parte do cotidiano local, se apresentou como uma temática de destaque no imaginário coletivo e na compreensão sobre as relações entre o esporte e a sociedade. Esse aspecto revela, entre outras questões, a influência midiática no repertório discursivo dos estudantes, que, ao se apropriarem dos símbolos, representações, linguagens e imagens televisivas, acabam por reproduzir em sua aprendizagem os sentidos atribuídos ao entretenimento e ao espetáculo midiático, cujos conteúdos, em grande parte, distorcem ou escamoteiam a realidade social (BETTI, 2004, p. 125).

Outro elemento estruturante presente no conteúdo das narrativas que recebeu a atenção de 19,2 \% dos estudantes diz respeito à realização da Copa do Mundo FIFA no Brasil no ano de 2014. O assunto foi abordado por meio de diversas óticas e apresentado em temáticas recheadas de ambiguidades, que se remeteram a motes como a mobilização em torno do megaevento esportivo e a possibilidade de consagração do "país do futebol", decorrentes de uma possível conquista do torneio pela seleção nacional, até temas como o questionamento e o descontentamento com relação aos vultosos investimentos públicos aplicados nas obras de construção dos estádios que sediaram os jogos em detrimento da falta de recursos a serem aplicados em setores básicos como a saúde e a educação. Sob esse aspecto, é possível atestarmos o grande impacto sociocultural e político que a realização do maior torneio de futebol do planeta gerou nas formas de consciência histórica em função da sua penetração midiática.

\footnotetext{
Os pontos negativos é que essa diversão vem sendo cada vez mais cara desde os preços dos ingreços [sic] até mesmo para comprar uma bola, e muita das veses [sic] um país que investe pesado no futebol como o Brasil, esquece de suprir necessidades básicas da população como educação, saúde e segurança. (Fragmento de narrativa produzido por um aluno da turma $1^{\circ} \mathrm{B}$, Escola 2 )

Mas também o futebol tem seus lados importantes [sic] e seus lados negativos [sic], tipo os investimentos com a copa do Brasil, porque eles tão [sic] gastando muito dinheiro com estágios [sic] de futebol ao invés de investir em hospitais, escolas, etc. (Fragmento de narrativa produzido por uma aluna da turma $1^{\circ} \mathrm{B}$, Escola 2).
}

Um número considerável de narrativas $(21,6 \%)$, nas quais foram elencadas temáticas relativas à politização da Copa do Mundo, indica que os alunos tiverem acesso, ainda que estivessem na condição de espectadores, ao amplo debate midiático que se constituiu em torno do megaevento esportivo. Ao proporem temas relacionados à distribuição de maior volume de recursos para as áreas consideradas mais deficitárias, como a saúde e a educação, os jovens revelam que suas opiniões políticas estão em 
sintonia com o discurso midiático, cujos conteúdos, de maneira ambígua, buscaram promover a competição esportiva, valorizando seu suposto "legado", enquanto, simultaneamente, dirigiam inúmeras críticas aos gastos públicos com a infraestrutura e a organização do megaevento esportivo (CAMPOS, 2015). O entrelaçamento da agenda política à agenda esportiva, iniciada nas jornadas de junho de 2013, às vésperas da realização da Copa das Confederações, ganhou corpo durante a cobertura jornalística da Copa do Mundo, quando a imprensa buscou retratar, simultaneamente, a pauta extensa e difusa das manifestações populares, que perderam força ao longo da competição, e os conteúdos relacionados à competição esportiva stricto sensu. Destarte, a memória dos estudantes construída sobre os tempos da Copa do Mundo de 2014 se apresenta, em boa medida, atrelada à produção discursiva da grande imprensa brasileira.

Quanto à avaliação das ideias substantivas, é possível notarmos a presença significativa de elementos simbólicos que denotam a preferência dos alunos pelo tema futebol espetáculo, representado pelos grandes clubes nacionais e internacionais, em detrimento do futebol amador.

\footnotetext{
O futebol para mim é um esporte que todos jogam para se divertir ou então estão querendo oportunidade para que sejam bons de bola e posa [sic] até estar nos time [sic] de grande importância como Cruzeiro, Flamengo, Botafogo entre outros. (Fragmento de narrativa produzido por um aluno da turma $1^{\circ} \mathrm{B}$, Escola 2).
}

Entre os elementos mais citados $(26,4 \%)$, destacam-se as referências à ascensão econômica proporcionada aos futebolistas oriundos das camadas empobrecidas da população e os altos salários pagos aos jogadores de futebol dos principais clubes profissionais. A incidência dessas temáticas, igualmente, revela a poderosa influência midiática no cotidiano dos estudantes, o que corrobora diretamente para a construção do conhecimento sobre a realidade social e, consequentemente, para a formação da consciência histórica. A superexposição midiática dos certames futebolísticos e das trajetórias de superação e glória de futebolistas, especialmente daqueles de origem pobre, cria um sentimento de identificação imediato entre os jovens - majoritariamente oriundos de camadas populares - com os ídolos televisivamente construídos.

A análise desse repertório discursivo dos estudantes pode ser subsidiada pelo entendimento das várias configurações assumidas pelo futebol no Brasil, cujos significados percorrem o conceito de "futebóis" desenvolvido pelo antropólogo social Arlei Damo (2003): 
A diversidade futebolística pode, então, ser agrupada nas configurações denominadas de: futebol profissional, também referido por alguns autores como futebol-espetáculo ou futebol de alto rendimento/performance; futebol de bricolagem, conhecido como fute, pelada, baba, racha e outras designações locais; futebol comunitário, em certos contextos nomeado de futebol de várzea e em outros como futebol de bairro ou amador; e o futebol escolar, vinculado à instituição escolar desde o século XIX, como dispositivo pedagógico de uso alargado e transformado em conteúdo da EFI ao longo do século XX. (DAMO, 2003, p. 136).

Embora pareça-nos perfeitamente possível a utilização dos aspectos relacionados às quatro matrizes configuracionais do futebol elaboradas por Damo (2003), procuramos compreender a preferência dos estudantes que participaram da pesquisa mediante uma breve explanação acerca de dois tipos ideais de futebol: o futebol profissional, também chamado de futebol espetáculo, e o futebol comunitário, que no contexto desta análise pode receber a alcunha de futebol de bairro ou futebol amador.

O aspecto da espetacularização do futebol é permeado por uma série de mecanismos que o diferencia das demais matrizes da modalidade. Inicialmente, observamos que o futebol profissional/espetáculo é alavancado pela divisão social do trabalho, que conta com um corpo de profissionais envolvidos diretamente na organização e prática regrada do futebol, profissionais especialistas em organizar uma narrativa em torno do futebol e levá-la ao grande público; e finalmente os torcedores, que absorvem profundamente a circularidade de emoções que carrega uma partida de futebol. Soma-se a esse conjunto de particularidades o grau elevado de excelência performática movida pelos interesses do público, que instaura a necessidade de dedicação absoluta da classe profissional envolvida, a qual recebe, em contrapartida, uma remuneração relativa ao trabalho desempenhado. Ademais, a exibição do futebol sob a tônica de um confronto estilizado e espetacularizado o torna uma espécie de rito agnóstico, vital para a produção e circulação de sentimentos derivados das situações criadas durante o espaço-tempo de uma partida propriamente dita. De forma especial, os interesses da indústria do espetáculo e o gosto popular permitem a classificação de alguns futebolistas como dignos e/ou muito dignos de compensação, seja financeira e/ou status social (DAMO, 2003, p. 138-140).

A matriz comunitária do futebol, por sua vez, é composta de boa parte dos elementos encontrados no futebol profissional; todavia, em escala reduzida. A organização de eventos fica restrita aos circuitos locais - cidades e bairros -, e o grau de envolvimento profissional é bastante precário. O futebol amador, como também é conhecido, tende a se constituir sob a forma de associações clubísticas que, por seu 
turno, se organizam por meio de associações mais extensas, as ligas. Há a possibilidade, entretanto, de algumas dessas associações apresentarem uma trajetória histórica dotada de certo sucesso e renome regional. Constatamos que a grande mídia especializada, possuidora de abrangências estadual e nacional, ignora abertamente a existência do futebol local e, em alguns casos, o notabiliza em decorrência de seus subprodutos improvisos, confusões etc. Cabe dizermos que o futebol amador, embora não apresente a mesma complexidade e ortodoxia do futebol profissional, especialmente em relação à sua organização, possui uma posição intermediária se comparado às demais configurações já citadas (DAMO, 2003, p. 142-144).

$\mathrm{Na}$ esteira dos argumentos formulados pelo antropólogo Arlei Damo (2003), é possível notar que a matriz espetacularizada do futebol, apesar de não ter sido estimulada pelos materiais históricos apresentados ao longo da execução do projeto de extensão, predominou entre diversas temáticas elencadas pelos estudantes em sua produção escrita. Ao se debruçarem sobre temas como a Copa do Mundo de 2014 ou a questão da ascensão econômica dos futebolistas profissionais, os estudantes apresentam em seus discursos os elementos mobilizados pela estética e pela retórica televisiva. Assim, é compreensível que um meio de comunicação de massa, amplamente difundido entre os diversos segmentos sociais como a televisão, seja capaz de interferir no processo de formação da consciência histórica, fornecendo valores, padrões de compreensão e de juízos morais, ou seja, arbitrando um modelo de representação da realidade social, cujo ethos se identifica deliberadamente com os interesses do mercado.

\section{Considerações finais}

A despeito da tradição centenária do futebol amador na cidade de São João delRei, a análise da produção escrita dos estudantes participantes do projeto de pesquisa e extensão "A história marca um gol" evidenciou que a formação da consciência histórica sobre o futebol local é pautada tanto pela tradição ligada ao futebol amador local, quanto pela lógica do establishment midiático, que se reproduziu nas narrativas, seja por meio das escolhas temáticas, pela coerência da organização das ideias ou pela capacidade demonstrada em articular o tema "futebol" às questões políticas que envolvem a sociedade brasileira.

Embora parte considerável da amostra tenha revelado a preferência dos estudantes em abordar temas ligados ao futebol espetáculo, a maioria dos relatos 
conseguiu, ainda que sem apresentar a devida coerência e profundidade, a capacidade de articular os saberes históricos cotidianos ao saber escolar. Com efeito, a estratégia de mobilizar a História Local, ilustrada pela história do futebol amador, nos permitiu estimular o interesse dos estudantes pelos conteúdos históricos atrelados a temáticas que aguçaram seus vínculos identitários, afetivos e, por conseguinte, sua historicidade.

As dimensões socioculturais e políticas que envolvem o esporte no Brasil, que nas últimas décadas têm despertado grande interesse dos historiadores, se constituem também como um conteúdo de grande empatia na perspectiva do ensino de história. Ao tornar inteligíveis os papéis dos agentes, das instituições e das dinâmicas sociais e políticas, o estudo histórico do futebol, seja da sua matriz espetacularizada ou amadora, possibilita não somente o desenvolvimento de aprendizagens específicas, como também viabiliza a compreensão de aspectos globais que permeiam as Histórias Local e Nacional.

Nessa perspectiva, o retorno ao argumento ruseniano, que relaciona $o$ entendimento da consciência histórica à dimensão da vida prática, permite-nos corroborar a tese de que a educação histórica é, inevitavelmente, construída por estéticas, discursos, saberes e valores incorporados nos mais variados espaços sociais. Cabe ao ensino de história, portanto, a tarefa de articular os conhecimentos prévios elaborados pelos estudantes, de modo a dar-lhes sentido no escopo da compreensão dos processos históricos. 


\section{REFERÊNCIAS}

BETTI, Mauro. A janela de vidro: esporte, televisão e educação física. 3. ed. Campinas: Papirus, 2004.

BOURDIEU, Pierre. O senso prático. 2. ed. Petrópolis: Vozes, 2011.

CAMPOS, Flávio de. A Copa da política em um país do futebol. In: MARQUES, José Carlos (Org.). A Copa das copas? Reflexões sobre o mundial de futebol de 2014 no Brasil. E-book. São Paulo: Edições Ludens, 2015.

DAMO, Arlei Sander. Monopólio estético e diversidade configuracional no futebol brasileiro. Movimento, Porto Alegre, v. 9, n. 2, p. 129-156, maio/ago., 2003.

DAMO, Arlei Sander. Paixão partilhada e participativa - o caso do futebol. História: Questões \& Debates, Curitiba, n. 57, p. 45-72, jul./dez., 2012.

EDWARDS, Verônica. Os sujeitos no universo da escola. São Paulo: Ática, 1997.

GERMINARI, Geyso D. O ensino de história local e a formação da consciência histórica de alunos do $6^{\circ}$ ano do ensino fundamental: uma experiência com a unidade temática investigativa. Anais do XIV Encontro Regional de História, Campo Mourão/PR, Universidade Estadual do Paraná, 2014. p. 355-363.

GRAÇA FILHO, Afonso de Alencastro. A princesa do oeste e o mito da decadência em Minas Gerais: São João del-Rei (1831-1889). São Paulo: Annablume, 2002.

LIMA, Alex Witney. O jogo de bola em terras mineiras: uma comparação entre a institucionalização do futebol em Belo Horizonte e São João del-Rei (1904-1921). 2014. Dissertação (Mestrado em História Comparada) - Universidade Federal do Rio de Janeiro, Rio de Janeiro, 2014.

LIMA, Alex Witney et al. As ligas desportivas de São João del-Rei (1930-1955): a busca pela afirmação do futebol local. Recorde: Revista de História do Esporte, Rio de Janeiro, n. 2, v. 2, p. 1-10, dez. 2009.

PARENTE, Regina. A narrativa na aula de história. In: BARCA, Isabel; SCHMIDT, Maria Auxiliadora. Educação histórica: investigação em Portugal e Brasil. Universidade do Minho: Braga, 2009. (Actas das Quintas jornadas internacionais de educação histórica). p. 79-114.

RÜSEN, Jörn. Razão histórica: teoria da história: fundamentos da ciência histórica. Brasília: Editora UnB, 2001.

SCHMIDT, Maria Auxiliadora. Perspectivas da Consciência Histórica e da Aprendizagem em Narrativas de Jovens Brasileiros. Tempos históricos, Marechal Cândido Rondon/PR, v. 12, p. 81-96, jan./jun. 2008.

SCHMIDT, Maria Auxiliadora; CAINELLI, Marlene. Ensinar história. São Paulo: Scipione, 2009. 